\title{
RECENT ADVANCES IN METEOROLOGICAL METHODS*
}

\author{
By SiR NELSON JOHNSON, K.C.B. \\ Director of the Meteorological Office
}

$\mathrm{T}$ $\mathrm{HE}$ making of weather forecasts is based on the construction of synoptic charts, which are prepared by plotting observations made simultaneously at places covering a wide area. Such a chart may include the whole of Europe, the North Atlantic Ocean and North America. Before the War, the observations made in each country and by ships at sea were broadcast from central stations at inter. nationally agreed times, thus enabling the meteorological services of each nation to collect reports covering the whole area. With the outbreak of war all enemy countries, and some neutrals, suppressed their reports, while the wireless silence imposed on ships prevented the reception of reports from the sea areas. Deprived of vital information in this way, the meteorologist was at the same time called upon to make forecasts in greater detail and with greater precision than before. It was mainly in an attempt to solve this problem that many of the devices described below originated.

Shortly before the War, the Americans had experimented with an automatic reporting station which could be set up, for example, on a small island, to provide regular reports without the necessity of maintaining a party of observers. The principle of this instrument is the same as that of the radio sonde which will be described later. The Germans exploited this idea in the form of a floating buoy which could be placed in the Atlantic Ocean by a submarine. The casing of the buoy consisted of a steel tube about 9 metres long and $50 \mathrm{~cm}$. diameter, surmounted by a tubular aerial some 8 metres high. Meteorological elements, carried inside the casing, measured barometric pressure, air temperature and sea temperature, and the readings were sent out by radio every six hours.

While ingenious, instruments of this type suffer from the fact that they do not give the information which would be of greatest value to the forecaster, namely, the state of the sky and wind-direction and speed. The buoy has the further disadvantage that its position is constantly changing.

The next instrument to be considered affords an illustration of turning to advantage something that is normally a nuisance. The loud cracks, or 'atmospherics', which are at times heard on every radio receiving set, are produced by lightning flashes-possibly several hundred kilometres away. Some years before the War, Sir Robert Watson-Watt had shown that the location of a lightning flash could be fixed by observing its apparent bearing from the two ends of a measured base-line. A method was thus at hand of ascertaining the existence and location of distant thunderstorms. The method would show when there were thunderstorms over Germany or on any part of the route to be taken by R.A.F. aircraft. Since thunderstorms are also frequently associated with the cold fronts of depressions, here was a means of obtaining information about approaching depres. sions and fronts.

The technique of the method consists in erecting two vertical frame aerials, one oriented in a northsouth direction and the other in an east-west direction.

\footnotetext{
* Royal Institution discourse delivered on November 30.
}

Such an aerial possesses the property of receiving a radio wave at maximum strength when the source of the wave is in the plane of the aerial ; waves striking the aerial normally, on the other hand, produce no effect. To indicate the relative strengths of the signals received by the two frame aerialsi, a cathode ray tube is arranged so that the spot of light is drawn out in a vertical direction by signals received by the north-south aerial and in a horizontal direction by signals received by the east-west aerial. By graduating the circumference of the cathode ray tube with a circular scale, it is possible to observe directly the bearing of a lightning flash by reading the inclination of the line produced on the cathode ray tube.

In practice, two small huts are provided at each observing station, one housing the two mutually perpendicular frame aerials and the other the recording apparatus. There are four such observing stations in the British Isles located in Bedfordshire, Cornwall, Northern Ireland and East Scotland. The stations are inter-connected by telephone to enable the officer controlling the observations to instruct the other three observers which lightning flashes to record. Observations are made about every three hours. The effective range of the equipment is about 1,500-2,000 km. The designing of the equipment and setting up of the stations was carried out by the National Physical Laboratory on behalf of the Meteorological Office.

In addition to providing the forecaster with useful information, the 'atmospheric' observations have proved valuable for investigating the distribution of lightning within cyclones. The frequency distribution of atmospherics, in relation to the warm and cold fronts of an occluded depression, shows that there is a maximum at the very apex of the warm sector, suggesting that the velocity of ascent of the warm air is also greatest at this point. It has also been found that whereas frontal atmospheries are most frequent about $80 \mathrm{~km}$. behind the cold front, there is a broad secondary maximum at about $650 \mathrm{~km}$. behind the front.

Another direction in which progress has been made is in the method of measuring the wind aloft, which is of such importance for aviation both in war and in peace. The normal method of following a pilot balloon by means of a theodolite is subject to the serious limitation that it cannot be used when the sky is cloudy. Two methods have been evolved for overcoming this limitation, one employing radio direction-finding and the other using radar technique. In the first method, a balloon is made to carry a small radio-transmitter which is 'followed' by three direction-finders located at the cormers of a triangle. The sides of the triangle are about $40 \mathrm{~km}$. long. By plotting the simultaneous bearing of the balloon from each of the three stations, its track can be followed from minute to minute. The balloon is filled to rise at about $6 \mathrm{~m} . / \mathrm{sec}$. and usually bursts at about $18 \mathrm{~km}$., when a parachute brings the transmitter down to the ground.

The bearing of the balloon and transmitter from each station is found by means of aerials of the 
Adcock type capable of rotation about a vertical axis situated midway between the di-poles. The receiving circuit is tuned to the frequency of the transmitter, and the aerial system is rotated until silence in the telephones indicates that the aerial is parallel to the wave front and thus normal to the bearing of the transmitter. An accuracy of about $0 \cdot 3^{\circ}$ can be obtained in the readings, but this can be achieved only if special attention is paid to the symmetrical construction of the aerial system, to the rigorous exclusion of all iron in the construetion of the observing hut, and to the careful selection of a suitable site. A suitable site is one that is flat, level and with a uniform subsoil. The elevation of neighbouring hills must not exceed $1^{\circ}$, and there must be no power-lines, buildings, trees, hedges or metal fences in the vicinity to refract the incoming beam. The Meteorological Office is again indebted to the National Physical Laboratory for having carried out much of the development work connected with this method of wind finding.

The second method of measuring the wind above clouds is by means of radar. In this case the balloon carries a special reflector instead of a transmitter. The ground equipment consists essentially of a shortwave transmitter and receiver, the emitting and receiving antennæ each situated at the foci of two paraboloidal mirrors $1.15 \mathrm{~m}$. in diameter. The framework which carries the mirrors can be rotated both in azimuth and elevation, and the indicating mechanism enables an operator to tell when the two mirrors are directed at the reflector on the balloon. In addition to giving the azimuth and elevation of the reflector, the receiver also shows the slant distance. From these three quantities the position of the balloon from minute to minute can be computed by simple trigonometry.

The special reflector carried by the balloon is made of metallized paper stretched on a light wooden framework, forming three mutually perpendicular surfaces-one horizontal and two vertical. This arrangement possesses the property of reflecting any incident beam back along its path. Although the reflector swings as it hangs below the balloon, the radar pulses are thus always sent exactly back to the receiver.

The wind determinations carried out on November 9, 1944, may be quoted as illustrating the type of information given by radio wind-finding. At noon on that day the wind velocity at $10 \mathrm{~km}$. was $41 \mathrm{~m} . / \mathrm{sec}$, while by midnight it had increased to $102 \mathrm{~m}$. $/ \mathrm{sec}$. Besides showing the existence of these strong winds, radio wind-finding has thus warned us how rapidly the wind at these heights is liable to change.

The wind is only one of the conditions aloft about which the meteorologist requires information. The other elements with which he is mainly concerned are pressure, temperature and humidity. These are measured by means of a radio sonde. This instrument is sent up on a free balloon rising at a rate of about $6 \mathrm{~m}$. $/ \mathrm{sec}$. It transmits continuously radio signals which enable the meteorologist on the ground to compute instantaneous values of the pressure, temperature and humidity from ground-level to a height which is usually about $15-18 \mathrm{~km}$.

A radio sonde consists essentially of two parts. First, there are the meteorologically sensitive elements -one responding to the pressure, another to the tem. perature and a third to the humidity of the atmosphere. The second essential part is the radio transmitter, together with mechanism for enabling variations in the meteorological components to impart corresponding variations in the radio transmissions.

Most radio sondes employ one of two principles. The first method is the chronometric method. The principle may be illustrated by imagining an arm to rotate uniformly. If there is a fixed contact at some point on the circumference, contact will be made at regular intervals equal to the period of rotation of the arm. If now another contect is introduced, the position of which is varied by a pressure-sensitive element, then the time interval between the fixed contact and the movable contact gives a measure of the pressure. If the circumference is divided into three, one sector can be allotted to pressure varia. tions, a second to temperature variations and a third to humidity variations. All that is necessary in this case, therefore, is to receive the transmitted radio message on a chronograph and to superimpose an accurate time-scale. This principle is adopted in the Canadian, Indian and French instruments.

The other main principle employed in radio sonde design is that of causing the meteorological element to vary the frequency of the radio transmission. Since the frequency of an electrical circuit is determined by its capacity, resistance and inductance, the frequency can be varied by changing any of these three quantities; in fact, radio sondes are in use in which the meteorological element is made to vary each of these quantities. In the very neat Finnish instrument the capacity of the circuit is varied. The American instrument varies the resistance, whereas the British instrument, of which the prototype was designed by the National Physical Laboratory, varies the inductance. There is a minor difference between these instruments. Whereas the Finnish radio sonde varies the fundamental frequency of its transmissions, the other instruments produce variations in an audio-frequency modulation imposed on the fundamental wave.

Space does not permit a detailed account of all these instruments and a brief description will therefore be given of the British radio sonde.

The cylindrical body of the radio sonde, $19 \mathrm{~cm}$. long and $14 \mathrm{~cm}$. in diameter, houses the radio trans. mitter with its low-tension and high-tension batteries. The three meteorological elements for measuring pressure, temperature and humidity are plugged in on the outside as separate units. Being detachable in this way, a damaged or defective unit can be quickly replaced. The sensitive portion of each unit is placed inside double-walled aluminium shields to protect it from radiation.

The upward movement of the radio sonde rotates a windmill which operates a rotary switch connecting each of the meteorological elements in turn with the radio transmitter.

The meteorological-sensitive elements can be described briefly. For measuring atmospheric pressure, use is made of an aneroid capsule. The expansion of the capsule as pressure diminishes is made to move an iron armature towards the poles of a U. shaped iron core, thus varying the inductance of the windings around the latter.

The temperature-sensitive element consists of a bi-metallic strip bent nearly to a circle to give greater rigidity. The metals are brass and invar steel. As this element coils or uncoils, the movement of its free end is again made to vary the distance of an armature from a similar iron-cored winding to that just referred to. 
The material now used for measuring the humidity of the atmosphere is goldbeater's skin. Like hair, goldbeater's skin extends when exposed to high humidity and contracts when placed in a dry atmosphere. It is superior to hair, which was used until recently, in that its response to a change of humidity is more rapid. As in the case of the pressure and temperature elements, the goldbeater's skin is made to move an iron armature to and from the poles of a magnet and so vary the inductance of the windings on the latter. Although the goldbeater skin hygrometer just described is probably the best available, it is by no means satisfactory since it becomes very inert at the low temperatures which occur in the upper atmosphere. Up to moderate heights it is reasonably good, but the only accurate instrument for measuring humidity at temperatures below $-25^{\circ} \mathrm{C}$. is the frost-point hygrometer, which will be described later.

Radio sonde ascents can be carried out in practically all weathers and they thus provide valuable information about the variation of the conditions in the high atmosphere and their relationship to the synoptic situation. The base of the stratosphere over England may be as high as $16 \frac{1}{2} \mathrm{~km}$. or as low as $7 \mathrm{~km}$. When it is high, the temperature in the stratosphere is sensibly uniform or increases slightly with height. When the tropopause is low, the temperature continues to fall slowly in the stratosphere so that at great heights it is nearly the same in both cases.

Aeroplanes were, of course, used regularly before the War for measuring upper air temperatures and humidities. The R.A.F. Gladiator Flights at Mildenhall in East Anglia and Aldergrove in Northerm Ireland established records for the regularity of their climbs of which they may well be proud. During the War, more of these Flights were formed and the climbs went up to $13 \mathrm{~km}$. as compared with $7 \frac{1}{2} \mathrm{~km}$. before the War. 'Spitfires' were generally used for this purpose.

Another type of meteorological flight was also undertaken with the object of securing information from the ocean areas. One route lay over the North Sea. A second ran $1,100 \mathrm{~km}$. northwards from the Shetland Islands, and the Atlantic Ocean was covered by several routes, including one emanating from Iceland. Some of these flights are still in operation.

The flights were planned to secure observations both at high levels and near sea-level. The outward flight was normally made at the $950 \mathrm{mb}$. levelabout $550 \mathrm{~m}$. above the sea--with descents every $400 \mathrm{~km}$. to obtain a pressure reading near sea-level. At the outward end of the track, temperature and humidity observations were made during a spiral climb to $500 \mathrm{mb}$. (about $5 \frac{1}{2} \mathrm{~km}$.). The aircraft returned half-way to its base at this height, and then descended to $950 \mathrm{mb}$. again, thus giving the vertical distribution of temperature and humidity at the half-way position. Each of these long flights of about $2,500 \mathrm{~km}$. was made every twelve hours--one sortie by day and one by night. For this duty 'Halifax' aircraft were provided by the R.A.F., and specially trained meteorologists were carried to make the observations.

The instrumental equipment included dry- and wet-bulb thermometers, a special aneroid barometer and a radio-altimeter. Non-instrumental observations were made of cloud, visibility, precipitation, and sea disturbance and swell. Wind-speed and direction would be derived from the drift of the aircraft. A special electrical thermometer was developed for measuring air temperature with an accuracy of about $\frac{1}{4}^{\circ} \mathrm{C}$. It is of the resistance type, temperature readings being made by obtaining a balance on a Wheatstone bridge. This method has been found to be free from certain sources of error which occur in the more common method of using the out-of-balance current to indicate the temperature. This instrument has proved particularly valuable on the ascents to $13 \mathrm{~km}$. carried out by the 'Spitfires'.

It will be noted that many of the new observational techniques considered aim at securing additional information about the upper atmosphere. The information so obtained is used for constructing charts for the upper levels of the atmosphere corresponding to the better-known surface charts. The upper air charts are, however, constructed on rather different lines. Instead of plotting isobars at a constant height, the British practice is to draw isopleths showing the height of the surface of selected values of pressure. The pressure-levels chosen are 1,000, 700, 500 and 300 millibars. The procedure consists in plotting first the $1,000 \mathrm{mb}$. surface chart by computation from the mean sea-level pressure readings. The thickness of the successive layers $1,000-700 \mathrm{mb}$., 700-500 mb., and 500-300 mb. are then computed from the upper air temperature and humidity observations given by the radio sonde and aircraft flights. By adding these thicknesses to the $1,000 \mathrm{mb}$. chart, a series of contour charts is obtained for each of the pressure-levels, $700 \mathrm{mb}$., $500 \mathrm{mb}$. and $300 \mathrm{mb}$. Charts are drawn every six hours giving a sequence showing the tendencies of temperature, thickness and height of the isobaric surfaces. In this way a three-dimensional picture is obtained of the structure of the atmosphere and of the air mass movements which are taking place. This three-dimensional representation of the atmosphere permits of a more certain analysis than can be made from surface charts alone. Upper air charts also enable direct forecasts of the wind, cloud and other conditions in the upper atmosphere to be made for aviation purposes.

One of the problems which the meteorologist was called upon to deal with during the War concerned the 'vapour trails' which formed such a conspicuous feature of the skies at the time of the Battle of Britain. It was shown theoretically that these trails are produced by the condensation of the water vapour in the exhaust of the aircraft engine. They usually occurred at a height of about $9 \mathrm{~km}$. and rarely below about $8 \frac{1}{2} \mathrm{~km}$. in summer and $6 \frac{1}{2} \mathrm{~km}$. in winter. It was also found from practical experience that the formation of a trail ceased if the aircraft climbed a short distance into the stratosphere. It was thus possible to advise pilots to climb into the stratosphere if they started making a conspicuous trail over enemy territory. The reason for the cessation of the trails in the stratosphere was assumed to be because the air in the stratosphere was so dry that the trail evaporated as fast as it was formed. But in the absence of any reliable instrument for measuring the humidity of the stratosphere it was not possible to verify this explanation.

An instrument has recently been developed by Dobson and Brewer which enables the humidity to be measured at the very low temperatures which occur in the stratosphere. It consists essentially of a copper thimble mounted above a Dewar flask containing petrol cooled by solid carbon dioxide. By means of a pump, the petrol can be made to impinge on the lower side of the thimble and cool it. The upper surface of the thimble is viewed through a. 
microscope and the cooling process is continued until hoar frost is seen to form. An electrical thermometer, either thermojunction or resistance type, is embedded in the thimble and enables the temperature to be noted when the hoar frost is formed. In practice, a small deposit is allowed to form and the temperature then adjusted so that individual crystals are seen neither to grow nor to evaporate. The thimble can be warmed by means of a small heating coil.

In a modified design Dobson has arranged the indication to be done by means of a photo-electric cell. A beam of light is directed obliquely on to the face of the thimble and the light scattered by the hoar frost deposit is focused on to the cell. A constant reading on the microammeter of the photo-cell indicates a steady condition of the frost deposit.

Fitted to an aeroplane, the instrument has yielded most important results in the hands of $\mathrm{Mr}$. Brewer. Up to the base of the stratosphere, the frost-point temperature is usually only slightly below the air temperature, thus indicating a fairly high humidity. As soon as the stratosphere is reached the air temperature rises but the frost temperature falls even more rapidly than before. At a distance of $2 \mathrm{~km}$. within the stratosphere the frost point may be more than $35^{\circ} \mathrm{C}$. below the air temperature, corresponding to a relative humidity of the order of 1 per cent.

The radio sonde and wind-finding technique have given us information up to a height of about $18 \mathrm{~km}$. To reach still greater heights, use has been made of a very high velocity gun. The shell is filled with smoke composition, and the smoke cloud produced at burst can be followed by theodolites to give both the speed and direction of the wind. A systematic series of wind determinations has been made at a height of $30 \mathrm{~km}$., although greater altitudes may be attainable.

Observations extending from February 1944 to May 1945 have shown that the wind at $30 \mathrm{~km}$. is mainly westerly during winter and easterly during summer. Actually the direction lies between about south-west and north-west in the first case, and between north-east and south-east in the second case. The change-over takes place in about April and October. Over the period covered by the observations, the mean velocity in winter was $37 \mathrm{~m}$. per sec. and in summer about $12 \mathrm{~m}$. per sec. The greatest velocity observed was $66 \mathrm{~m}$. per sec. from a direction $285^{\circ}$ (true). This observed seasonal change in the wind at this level confirms a prediction made by the late Dr. F. J. W. Whipple from his study of the audibility of explosions at long distances. It is hoped that a full account of these wind measurements will be published shortly by Flight-Lieutenant Murgatroyd, the meteorological officer who has been associated with the work.

It will have been noted that most of the methods described above are concerned with increasing our knowledge of the conditions in the upper atmosphere. This is symptomatic of the whole trend of modern meteorology. It has now become possible to study the atmosphere in three dimensions as a matter of routine, instead of confining our attention to the phenomena occurring at ground-level. This new outlook constitutes the greatest advance made in meteorology in recent times.

We have, however, only just begun to use these now instruments and techniques, and there is every reason to believe that their continued employment will yield results of the greatest importance to the science of meteorology.

\section{DEVELOPMENT IN THE SCIENTIFIC INSTRUMENT INDUSTRY IN GREAT BRITAIN}

$T$ HE vital part played by scientific and technical research in the Second World War is recognized by everyone-radar, high-speed aircraft, magnetic mines, degaussing, Pluto, Fido, and now atomic energy, are only a few of the many achievements of science and engineering of which we now hear so much. Cabinet ministers and the Press have paid high tribute to such achievements and we are justified in hoping that there is a better future in store for scientific research in Great Britain.

It is important not to forget, however, that modern science cannot make satisfactory progress without an adequate supply of good scientific instruments. Not much more than a generation ago, scientific instruments as now understood scarcely existed. The equipment of university research laboratories was very poor indeed, judged by modern standards : a few reflecting galvanometers, voltmeters and ammeters, with possibly a vibration galvanometer and a Duddell or Einthoven oscillograph, were the main equipment of many electrical laboratories. Valves were not in common use until some time after the First World War. Cathode ray oscillographs, now almost as common as valves, came on the market in small numbers about twenty-five years ago.

The magnificent array of scientific instruments which are now manufactured in Great Britain is testimony to the vigorous growth of the scientific instrument industry during the past twenty or thirty years. During the war years 1939-45, the development has been most remarkable. Many in. struments previously in very short supply have reached the mass-production stage without loss of accuracy and reliability; some of the older measuring instruments have been modernized, and new designs have been produced to meet special war-time requirements. The necessities of a 'scientific war' have called for an outstanding display of ingenuity, both in the design and construction of scientific instruments.

A clear indication of the present state of develop. ment and importance of the industry was provided in the recent exhibition of scientific instruments organised by the Physical Society at the Imperial College of Science and Technology, South Kensington. In normal times the exhibition is held annually, but the War enforced a long break between the twenty. ninth exhibition held in January 1939, and the thirtieth held in January 1946. The abnormally long interval between these exhibitions, combined with the exceptional demands of war, served to reveal more clearly the remarkable progress made by the industry in this period. It is of interest to observe also that exhibits which once appeared in the Research Section of the exhibition now appear in the Industrial Section. As evidence of the national importance of the exhibition, it was opened by Sir Stafford Cripps, president of the Board of Trade. In his opening remarks he referred to the excellent achievements of the scientific instrument industry in Great Britain during the six years of war. Referring to mass production, he said, "instead of debasing their standards by introducing volume production, they have carried into that mass production the skill and accuracy which they had long cultivated in their specialized 